\title{
Stimulus Conduction in Atria Studied by Means of Intracellular Microelectrode
}

\author{
Part II. That Around Atrioventricular Ring
}

\author{
Maretsugu HoRIBA, M.D.
}

\begin{abstract}
The sinus impulse is transmitted to the right atrium through crista terminalis and mm. pectinati. The impulse is terminated at atrioventricular ring region and is not transmitted directly beyond the ring. The impulse to the ventricles passes only through atrioventricular node and His bundle. In what region is the impulse interrupted? The nature of the spread of excitation on atrial musculature in the very vicinity of the ring in the isolated mammalian heart was studied by means of intracellular microelectrode. The cells in this region are expected to be making a change in electrophysiologic behaviors.
\end{abstract}

7 HE impulse originated in the cardiac pacemaker is transmitted in the 1 first place to the sinus node musculature surrounding the pacemaker causing the activation of itself, ${ }^{11},{ }^{2}$ ) while the impulse toward the atrioventricular node ( $\mathrm{A}-\mathrm{V}$ node) is transmitted rather quickly through the both branches of crista terminalis of the right atrium ${ }^{2), 3}$ and the impulse toward the left atrium through the Bachmann's bundle. ${ }^{4)-6)}$ The musculature of the right atrial roof is activated by the stimulus transmitted through $\mathrm{mm}$. pectinati via crista terminalis. ${ }^{2), 3)}$ The right atrial musculature to be activated last of all is that surrounding atrioventricular ring (A-V ring).

Under the physiologic condition, the atrial activation is transmitted to the ventricular musculature only through the A-V node, that is, the activation affecting the peripheral musculature of the atrium can not be transmitted directly to the ventricular musculature beyond the connective tissue of the $\mathrm{A}-\mathrm{V}$ ring. The electrophysiologic function of the musculature in the very vicinity of the $A-V$ ring except the $A-V$ node are still obscure. To give a clue for a question why the atrial activation can not be transmitted directly to the ventricular musculature, electrophysiologic activities of the atrial musculature in the vicinity of the $\mathrm{A}-\mathrm{V}$ ring were studied by means of microelectrode method.

From the First Department of Internal Medicine (Director: Prof. Susumu Hibino, M.D.), School of Medicine and the Research Institute of Environmental Medicine (Director: Prof. Hideo Toyoshima, M.D.), Nagoya University, Nagoya. 


\section{Method}

Twelve healthy adult mongrel dogs weighing about 5.0 to $10.0 \mathrm{Kg}$. and 5 healthy adult rabbits weighing about 2.0 to $2.9 \mathrm{Kg}$. were anesthetized with pentobarbitrate. Then the chest was opened and the heart was cut out without giving any unordinary tension and was removed into a receptacles filled with Tyrode's solution as quickly as possible. The chemical composition and the condition of Tyrode's solution were the same as those reported in the preceding paper part I.6) Both of the left and right ventricular musculature were cut away at the line about $1 \mathrm{~cm}$. distant from the $\mathrm{A}-\mathrm{V}$ ring. The left atrial musculature was also cut away from the border to the intra-atrial septum. The right atrial free wall was cut open and the endocardial surface was exposed. As may be seen in Fig. 1, the specimen consists of whole musculature of right atrium, basal part of vena cavae and small strip of right ventricular musculature adjoining the right atrium. The tricuspid valve was cut off from its base.

The prepared specimen was then transferred into thermostatic bath filled with oxygenated Tyrode's solution and was pinned to paraffin block turning the endo-

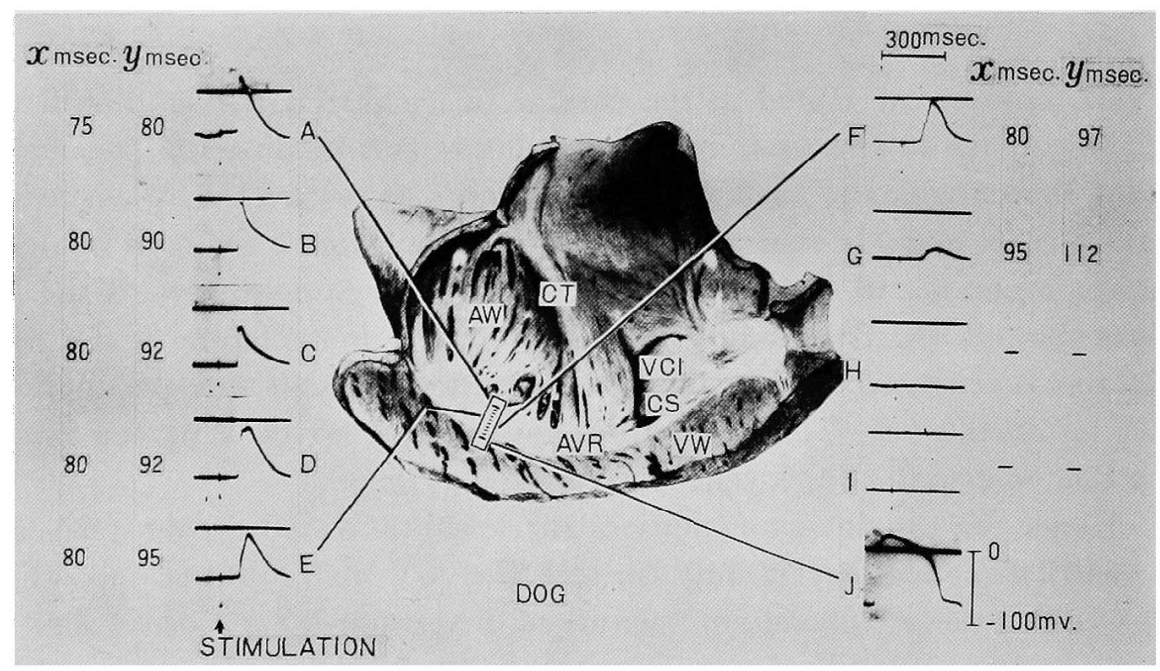

Fig. 1. Sketch of the endocardial surface of the right atrium.

$\mathrm{AW}=$ right atrial free wall, $\mathrm{AVR}=$ atrioventricular fibrous $\mathrm{ring}, \mathrm{CS}=$ coronary sinus orifice, $\mathrm{CT}=$ crista terminalis, $\mathrm{VGI}=$ vena cava inferior, and $\mathrm{VW}=$ ventricular wall.

The traces of right and left columns illustrate the configuration of transmembrane potentials and the instance of the stimulation. The exploration was made at the regular interval of $1 \mathrm{~mm}$. along a line vertical to the $\mathrm{A}-\mathrm{V}$ ring. The line was located $1 \mathrm{~cm}$. posteriorly from the posterior margin of coronary sinus orifice. The $\mathrm{x}$ means the time interval from stimulation to the onset of initial slow component of the depolarization (point $\mathrm{X}$ ). The $\mathrm{y}$ means the time interval from the stimulation to the onset of the sharp upstroke of the depolarization (point $Y$ ). In each trace, the upper horizontal line illustrates electric zero level. 
cardial surface up. For the high sensitiveness of the specimen to the pressure, it was very important to keep preparation free from any unnatural tension.

The experiments were carried out under artificial electric driving stimulated sinus node or under natural sinus rhythm. As a driving electrode, enamel coated $\mathrm{Ag}-\mathrm{AgCl}$ wire $100 \mu$ diameter was used. Stimulation was given bipolarly through a pair of contiguous electrodes (distance between 2 electrodes was about $2 \mathrm{~mm}$.) applied at a some point of the endocardial surface at the basal part of superior vena cava in the vicinity of crista terminalis. The sinus node was suspected to be in this area.

The electric stimulator and the frequency, intensity, and duration of the stimulus utilized were the same as those reported in the preceding paper. Transmembrane potentials were recorded from muscle fibers in the vicinity of the A-V ring by the use of a microelectrode which was the same as that employed in the preceding paper.

Penetrations were performed at equalized intervals along several lines in both the vertical and parallel direction to the A-V ring. Each distance of the point penetrated was measured as exactly as possible through the use of a vernier scale attached to the micromanipulator by which the microelectrode was kept holding. The location of the point where the penetration was performed was observed by stereomicroscope. The amplifier, oscilloscope and long recording apparatus utilized in the present study were the same as those reported in the preceding paper.

When the experiment was performed under natural sinus rhythm, a unipolar lead electrogram was recorded from a certain point of endocardial surface and was used as a time reference. When the experiment was performed under artificial driving, the activation time was conventionally given by the time interval from escaped current to the onset of the rapid depolarization upstroke of membrane action potential.

In the very vicinity of the $\mathrm{A}-\mathrm{V}$ ring, however, the membrane action potential displayed slower upstroke than that from the other part of atria, for example, the atrial free wall, the crista terminalis ${ }^{2,3)}$ or the Bachmann's bundle. ${ }^{6)}$ Therefore it was difficult to know where was the exact point of the firing of cell penetrated. To give a clue for this question, the author tried an experiment as follows. After a cell was penetrated and the membrane potential was recorded, the tip of the microelectrode was snapped away by a small forceps keeping free from the displacement of the electrode position. Then the tip of tube was softly touched again to the endocardial surface of the atrium to lead unipolar electrogram. The point thus touched again could be located very close to the point where the tip of microelectrode had penetrated the cell and made it possible to record the unipolar lead electrogram and the membrane action potential from almost the same point. These 2 records thus obtained were utilized for the determination of the onset of the membrane action potential.

Usually, the exploration could be continued for about 1 hour without causing discernible changes in conduction rate and membrane resting and action potentials.

\section{RESULTS}

1) Activation times in the vicinity of the A-V ring

Fig. 1 shows an instance of the experiments. The membrane potentials were recorded from cells along a line transversal to the A-V ring. The ex- 
ploration was made at the regular intervals of $1 \mathrm{~mm}$. along a line $1 \mathrm{~cm}$. posteriorly from the posterior margin of coronary sinus orifice.

The trace at the top of the left column (labelled A) was from a cell $5 \mathrm{~mm}$. distant from the $\mathrm{A}-\mathrm{V}$ ring. Those from the second to the bottom (labelled B, C, D and E) were from cells distant 4, 3, 2 and $1 \mathrm{~mm}$. respectively from the ring. The top of the right column (labelled $\mathrm{F}$ ) was the trace from a cell of the atrial musculature immediately near the A-V ring. The traces from the second to the fourth (labelled $\mathrm{G}, \mathrm{H}$ and I) were from cells in the $\mathrm{A}-\mathrm{V}$ ring region itself, and the last trace (labelled $\mathrm{J}$ ) was from a cell of the ventricular musculature beyond the ring.

As may be seen in the traces $B$ to $F$ of this figure, there was an initial slow component preceding the rapid upstroke of depolarization. This component, however, bore the question whether it was caused by depolarization itself of the cell penetrated or reflected the potential change extrinsic to the cell.

As an aid to giving answer for this question, the QRS complex of the unipolar lead electrogram led from an almost the same point was compared with the depolarization upstroke of the membrane action potential (Fig 2). The technique was described in the chapter "Method". It was observed that the onset of the $R$ wave of the unipolar lead electrogram was synchronous with the onset (referred to point $\mathrm{X}$ ) of the small initial slow component of membrane action potential.

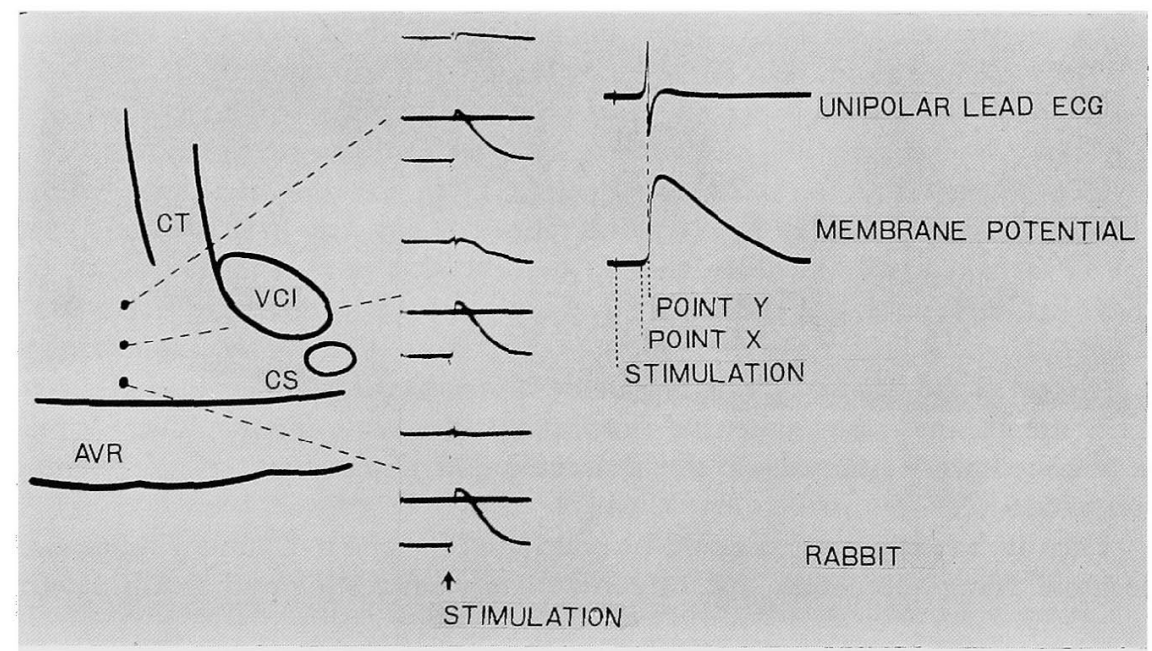

Fig. 2. The QRS complex of the unipolar lead electrogram, led from the same point where the microelectrode was plunged, was compared with the depolarization upstroke of the transmembrane potential. Right column is a series of the records from 3 points explored. Left column schematically illustrates the relationship between the unipolar lead and intracellular electrograms. 
The onset of the sharpest downward deflection of the intrinsic deflection in the unipolar lead electrogram was nearly synchronous with the onset (referred to point $\mathrm{Y}$ ) of the sharp upstroke of the membrane action potential.

From these findings, it was suspected that the small initial slow component of the membrane action potential may reflect the potential change extrinsic to the cell (see discussion). In Fig. 1, if some one compares the time interval from the escaped current of stimulus to the point $\mathrm{X}$ in each trace, it will be found that there is no appreciable difference in interval between them except 2 differences beween $\mathrm{A}$ and $\mathrm{B}$ measured as 5 msec., and between $\mathrm{F}$ and $\mathrm{G}$, $15 \mathrm{msec}$. On the contrary, if some one compares the time interval from the escaped current to the point $\mathrm{Y}$ in each trace, it will be found that the time interval gradually prolonges as the electrode approaches to the A-V ring. The difference in time interval between the traces $\mathrm{A}$ and $\mathrm{F}$ was measured as 17 msec. and that in the traces $F$ and $G, 15 \mathrm{msec}$.

Fig. 3 shows another case of the experiment. Exploration was made along the transversal line distant $1.5 \mathrm{~cm}$. anteriorly from the anterior margin of coronary sinus orifice. The trace in each row shows the unipolar electrogram (the upper) and the membrane action potential (the lower). The experiment was carried out under the condition of spontaneous natural sinus rhythm. The membrane action potential in the top row (A) was recorded

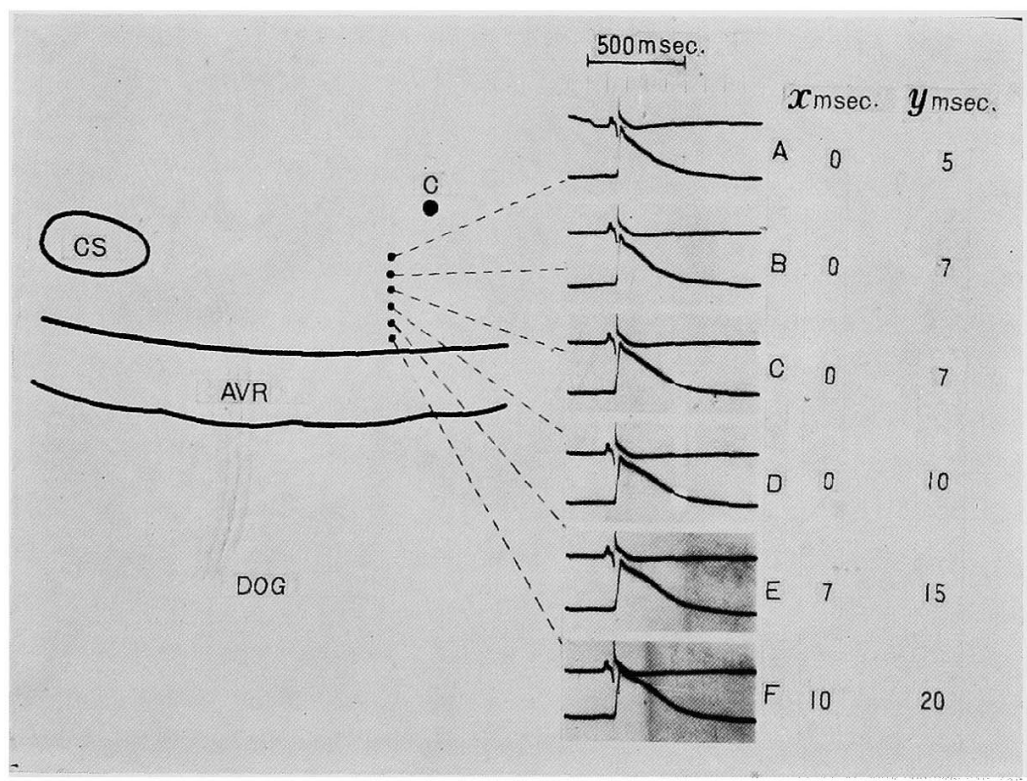

Fig. 3. Illustrates intracellular records and their $\mathrm{x}$ and $\mathrm{y}$ time intervals from serial points in the vicinity of the A-V ring. The records are obtained exploring along line transversal to the $\mathrm{A}-\mathrm{V}$ ring at each $1 \mathrm{~mm}$. distance.

$\mathrm{C}=$ The location of the electrode of the unipolar lead electrogram utilized as a time reference. 
from a cell distant $6 \mathrm{~mm}$. from the $\mathrm{A}-\mathrm{V}$ ring. The time interval from the onset of the intrinsic deflection to the point $\mathrm{X}$ or $\mathrm{Y}$ was measured on each trace as a provisional activation time of the cell penetrated and was compared each other.

When the time interval up to the point $\mathrm{X}$ was measured as a provisional activation time, there was no appreciable difference in activation time between the traces from A through $\mathrm{D}$, and 10 msec. of difference between the traces from $\mathrm{D}$ to $\mathrm{F}$. On the contrary, when the time interval up to point $\mathrm{Y}$ was measured as a provisional activation time, there was gradual delay in the activation time as the $\mathrm{A}-\mathrm{V}$ ring was approached and the difference in activation time between traces $\mathrm{A}$ and $\mathrm{F}$ was measured as 15 msec.

The activation times of cells in the vicinitiy of the A-V ring were about 50 to $70 \mathrm{msec}$. on the rabbit heart and 70 to $100 \mathrm{msec}$. on the canine heart when they were measured at the point Y. They were varied from rabbit to rabbit or from dog to dog. On each experimental animal, however, these values were almost fixed and were roughly the same everywhere along the $\mathrm{A}-\mathrm{V}$ ring cxcept the A-V node (Fig. 4). The deviation of these values was less than $10 \%$ of the mean value.

In order to know the attitude of the stimulus transmission in the vicinity of the $\mathrm{A}-\mathrm{V}$ ring, the author tried following experiment. In the vicinity of the

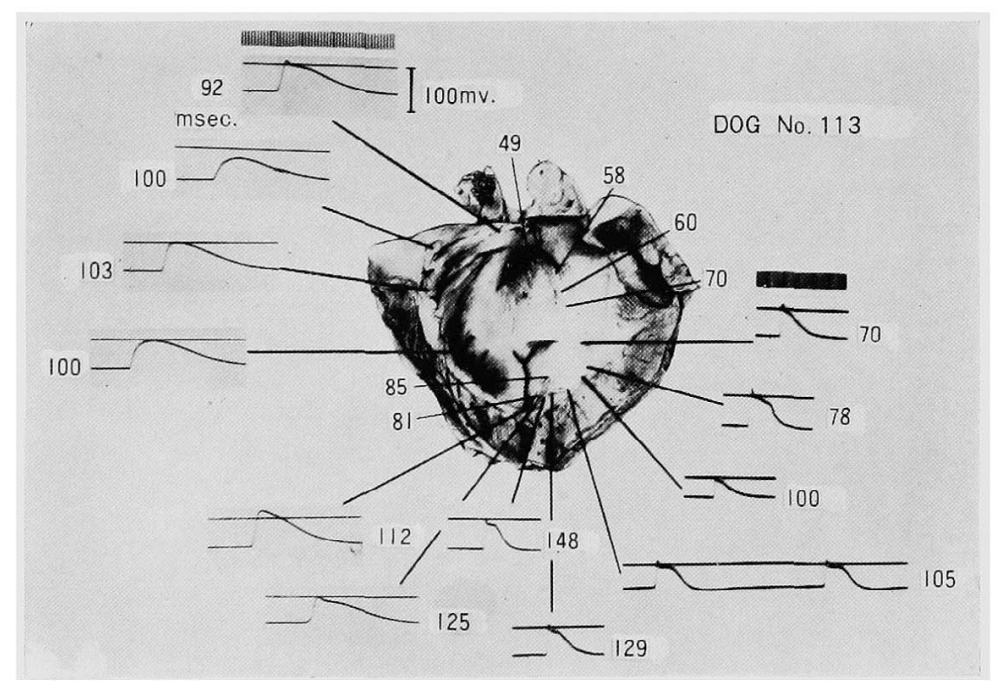

Fig. 4. Illustrates the intracellular records and their activation times from the atrial musculature in the vicinity of the A-V ring. Recording paper runs at 2 different speeds. The right group of the traces was recorded by higher speed as much as twice than the left group. The activation times at the various points in the vicinity of the ring are measured almost the same instance and it is about $100 \mathrm{mscc}$. 


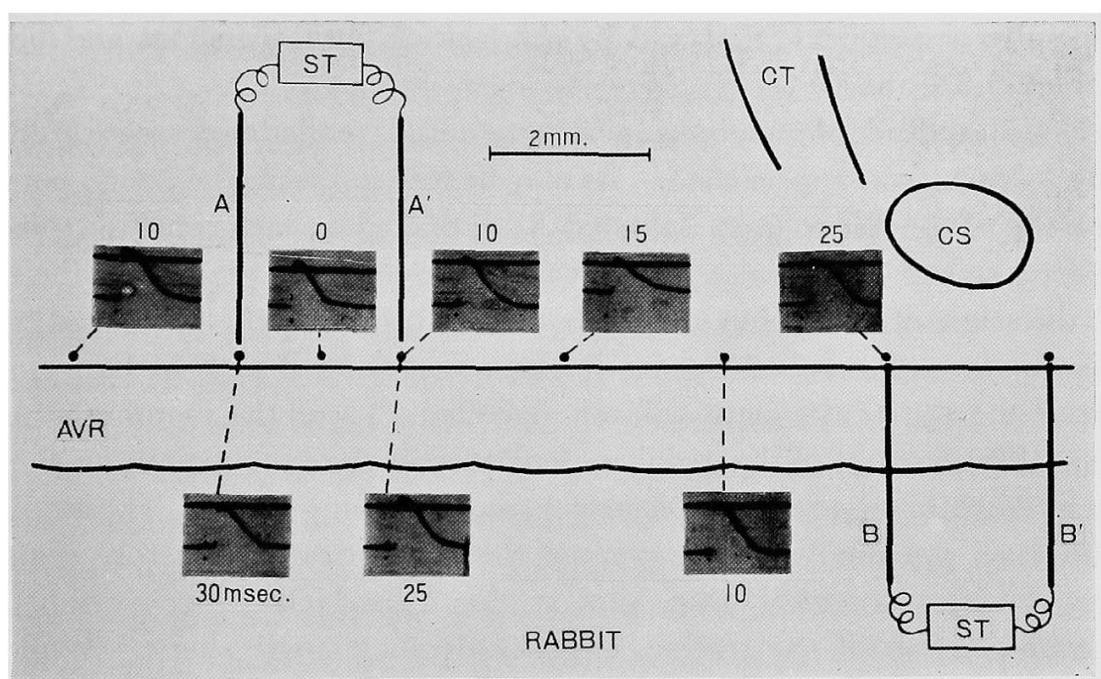

Fig. 5. Illustrates the configuration of the membrane potential and the arrival time of the activation. The electric stimulus was applied at the atrial musculature in the vicinity of $\mathrm{A}-\mathrm{V}$ ring. The upper traces reproduce the membrane potentials from a series of point along $\mathrm{A}-\mathrm{V}$ ring as they appear when the stimulus was given through the left stimulus electrodes $\left(\mathrm{AA}^{\prime}\right)$. The lower traces, the stimulus was given through the right stimulus electrodes $\left(\mathrm{BB}^{\prime}\right)$.

$\mathrm{A}-\mathrm{V}$ ring, 2 couples of stimulus electrode were placed along the $\mathrm{A}-\mathrm{V}$ ring keeping a certain distance to give an artificial stimulation to the atrial musculature, and the membrane action potentials were recorded from the cells at various distances from each of the stimulus electrodes giving a stimulation through the electrodes of either side.

The upper traces in Fig. 5 reproduces the membrane action potentials from a series of points along the $\mathrm{A}-\mathrm{V}$ ring as they appear when the stimulation was given bipolarly through the stimulus electrodes in the left side (AA'). The location of the stimulus electrodes (AA') was $7 \mathrm{~mm}$. posteriorly (measured at the mid point of the 2 electrodes) from the posterior margin of the coronary sinus orifice. Each figure expressed the activation time. The lower traces, in Fig. 5, reproduce the membrane action potentials from a series of points along the A-V ring as they appear when the stimulus was given through the right sided electrodes ( $\left.\mathrm{BB}^{\prime}\right)$. The locations of the points where the traces were obtained were nearly the same in both series of exploration. The conduction velocity of the atrial musculature in this region was measured as about $0.3 \mathrm{M}$./sec. in both directions.

2) Transmembrane potentials

Membrane action potential recorded from the atrial musculature in the vicinity of the $\mathrm{A}-\mathrm{V}$ ring was characterized by slow upstroke exhibiting no 
sharp spike at the peak of it and by the lack of both overshoot and plateau (see Figs. 1,3,4 and 6).

The amplitude of membrane action potentials tended to decrease gradually as the A-V ring was approached. As may be seen in Fig. 1, the action potential at the top of the left column (labelled A) displayed a sharp rapid upstroke followed by spiked overshoot. There was no appreciable plateau in the trace. The duration of the rising phase, however, progressively prolonged as the A-V ring was approached as seen in the traces from B to F in Fig. 1. The trace at the top of the right column (labelled $F$ ) was the membrane action potential from a cell of the atrial musculature in the very vicinity of the A-V ring, and exhibited a remarkable prolongation in rising phase. The amplitude of the trace was small and the peak of the depolarization upstroke remained under the zero potential level, that is, the trace lacked the overshoot and the configuration of the trace was generally in triangle shape. While the rising phase of depolarization prolonged progressively as the $\mathrm{A}-\mathrm{V}$ ring was approached, in the region of the $\mathrm{A}-\mathrm{V}$ ring itself, the membrane action potential was quite small in amplitude and showed a dome shape in its configuration as seen in the second row of the right column (labelled $G$ ) or there was no appreciable action potential as seen in the traces $\mathrm{H}$ and $\mathrm{I}$. The trace at the bottom of right column (labelled $\mathrm{J}$ ), was a trace obtained from a cell of the ventricular musculature and displayed a sharp upstroke followed by spiked overshoot, prolonged plateau and gradual return to membrane resting potential. This kind of trace was obtained from the ventricular musculature beyond the A-V ring. These changes in membrane action potential

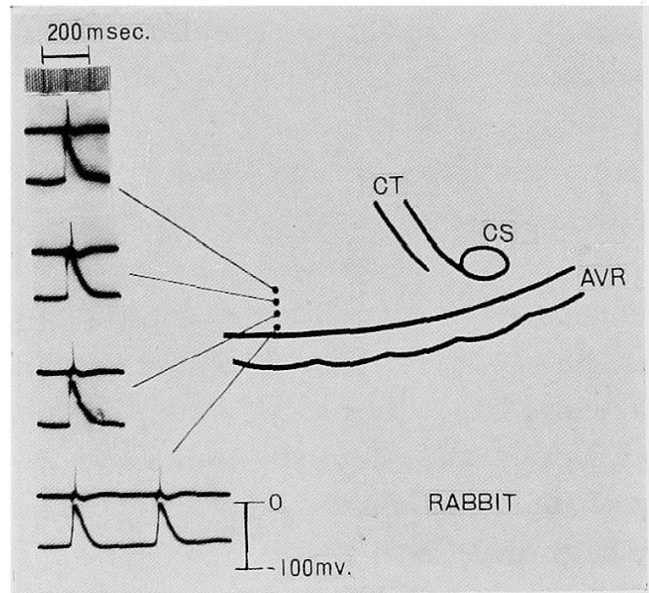

Fig. 6. Illustrates intracellular record showing the diastolic slow depolarization. The exploration was made along a line transversal to the A-V ring. The line located at $0.8 \mathrm{~cm}$. posteriorly from the posterior margin of coronary sinus orifice. 
were observed with the specimen undergoing artificial driving. The general characteristics of these change were nearly the same as those with an atrial specimen spontaneously contracting under natural sinus rhythm. There was no appreciable difference in the changes of membrane action potential between the canine and rabbit hearts.

The membrane action potential recorded from a cell in the A-V node region often displayed a slow diastolic depolarization (Fig. 4). The membrane action potential showing the slow diastolic depolarization was also found occasionally ( 3 cases in 8 rabbits, 1 case in 6 dogs) in a localized atrial musculature in the vicinity of the A-V ring. The location of this localized musculature in the vicinity of the $A-V$ ring was 0.8 to $1.2 \mathrm{~cm}$. (in rabbit) or $1.5 \mathrm{~cm}$. (in $\operatorname{dog}$ ) posteriorly from poterior margin of coronary sinus orifice. One of these cases was shown in Fig. 6. In this figure, each distance of the points explored was $5 \mathrm{~mm}$. and the trace at the bottom row was the membrane action potential recorded from a cell in the adjacent part of atrial musculatrue to the $\mathrm{A}-\mathrm{V}$ ring.

\section{Discussion}

It was reported by Easton, ${ }^{7)}$ Prinzmetal et al., ${ }^{8)}$ and $\mathrm{Sano}^{97}$ that even an intracellular electrogram can reflect the potential change extrinsic to the impaled cell. In the present paper, it is also necessary to give a consideration to the extrinsic factor to discuss the instant of the onset of the membrane action potential. As it was described in the preceding chapter, the membrane action potential from the atrial musculature in the very vicinity of the A-V ring displayed a small initial slow component preceding sharp upstroke of depolarization. This component bore a question in the point whether it was a part of the membrane action potential of the cell penetrated itself or reflected the potential change extrinsic to the cell penetrated. As may be seen in Fig. 2, the onset of the $\mathrm{R}$ wave of the unipolar lead electrogram was synchronous with the onset of the small initial slow component (referred to point $\mathrm{X}$ ) of the membrane action potential, and the onset of the sharp upstroke of the membrane action potential (referred to point $\mathrm{Y}$ ) was within the duration of so-called intrinsic deflection of the unipolar lead electrogram. These findings gave rise to the suspicion that the small initial slow component may not necessarily reflect the potential change resulting from the depolarization of the cell penetrated itself.

This was more strongly suspected by the following 2 observations. 1: The trace characterized by a small initial slow component of the membrane action potential could be only obtained from the area where the trace of 
unipolar lead electrogram displayed the $\mathrm{R}$ wave. 2: According to the author's coworker, ${ }^{2)}$ the right atrial excitation is transmitted along $\mathrm{mm}$. pectinati via crista terminalis to the $\mathrm{A}-\mathrm{V}$ ring with the conduction velocity of about $1 \mathrm{M}$./sec. If the point $\mathrm{X}$ is assumed to be indicative of the onset of the cell activation, the cells at the points B, C, D, E and F in Fig. 1 and A, B, C and D in Fig. 3 have to be affected by the activation at almost the same instant. Thus the transmission of the atrial excitation abruptly changes its behavior at a place in the vicinity of the $A-V$ ring. On the contrary, if the point $Y$ is selected as the instant indicative of the onset of the activation of the cell penetrated itself, there is a gradual delay in onset of the activation as the A-V ring is approached and it demonstrates that the atrial excitation in the vicinity of the $\mathrm{A}-\mathrm{V}$ ring is conducted without giving any abrupt change in its sequence of transmission.

It was reported ${ }^{10}$ ) that the onset of depolarization coincides with the beginning of the QRS complex in adjacent surface electrocardiogram. According to Toyoshima et al., ${ }^{11}$ the time of arrival of cardiac activation in ECG lies somewhere in the duration of the intrinsic deflection. Since the findings that the point $\mathrm{X}$ was usually synchronous with the onset of the $\mathrm{R}$ wave and the point $\mathrm{Y}$ was synchronous with some point in the duration of the intrinsic deflection of a closely adjacent unipolar lead electrogram, the onset of the activation may be given by the onset of the sharp upstroke of membrane action potential.

The activation times at various points along the very vicinity of the A-V ring were observed to be almost the same in each experimental animal. These values were measured as 50 to $70 \mathrm{msec}$. on rabbit heart and 70 to $100 \mathrm{msec}$. on canine heart. The deviation of these values on each animal was less than $10 \%$ of the mean value. This value was quite agreeable with that reported on rabbit heart by Paes de Carvalho et al. ${ }^{12}$

The activation times at serial points along the vertical line to the $A-V$ ring were gradually delayed as the A-V ring was approached and the conduction velocity in this region was measured as about $0.3 \mathrm{M}$. $/ \mathrm{sec}$. This value was very small compared with those of the crista terminalis and of $m$. pectinatus. ${ }^{2), 31}$ The conduction velocity of the atrial musculature along the A-V ring was also measured as about $0.3 \mathrm{M}$./sec. as shown in Fig. 5 .

It is known that the sinus excitation in normal mammalian heart is transmitted from atrium to ventricle only through the A-V node and the His bundle. As in usual experiment, the atrial excitation was not directly transmitted to the ventricular musculature beyond the $A-V$ ring. Why the atrial excitation approached to the A-V ring is terminated at the ring and is not transmitted to the ventricular musculature beyond the ring? As shown in the present experiment, the action potentials of the atrial cells in the vicinity 
of the A-V ring displayed gradual change in their slope and amplitude of depolarization upstroke as the ring was approached. This may be caused by the changes of cells in their electrophysiologic behaviors. Two factors, the decreases in the slope and the amplitude of depolarization upstroke will give a less effect as a stimulus. The existence of the tricuspid valve between the atrium and the ventricle may also be responsible to the interception of atrioventricular stimulus conduction.

It was reported, however, by Glomset et al. ${ }^{131}$ that many muscular bridges between the atrium and ventricle were found in the atrioventricular groove. In the present experiments, there were no muscular connections between the atrium and ventricle observed. Even the muscular connection between the atrium and ventricle lie anywhere, the cells in the vicinity of the A-V ring changing in the electrophysiological behaviors will interrupt the transmission of atrial excitation.

According to Patten, ${ }^{14)}$ " normal P-R interval exist in the embryo at a time when the connections all around the $A-V$ ring are intact, is showing that the delay is a characteristic of the $A-V$ ring tissue and not of the $A-V$ node in particular." The shape of the membrane action potential recorded from the cells in the vicinity of the $A-V$ ring was similar with that from the $A-V$ node ${ }^{15)}$ and the diastolic slow depolarization, so called pacemaker potential, was often recorded from a cell group localized in a region posteriorly to the coronary sinus orifice. This may be caused by the similar structure of the cell group either to the $\mathrm{A}-\mathrm{V}$ ring or $\mathrm{A}-\mathrm{V}$ node. From the histological view point, "a wreath of ganglion cell nerve fibers surrounds the heart in the atrioventricular groove" 13 ) and embryologically the A-V ring is closely related to the A-V node. ${ }^{16)}$

\section{SUMMARY}

The nature of the spread of excitation of atrial musculature in the very vicinity of the $\mathrm{A}-\mathrm{V}$ ring was studied by means of intracellular microelectrode. The records obtained from this region showed progressive decreases in depolarization rate and amplitude of the depolarization upstroke as the $\mathrm{A}-\mathrm{V}$ ring was approached. These 2 factors, the decreases in the rate and amplitude, will give a less effect as a stimulus.

The shape of the membrane action potential recorded from the cells in this region was similar with that from the A-V node and the diastolic slow depolarization was often recorded from a cell group localized in the region posteriorly to the coronary sinus orifice.

The QRS complex of the unipolar lead electrogram led from the same 
point where the microelectrode was plunged was compared with the depolarization upstroke of the membrane action potential. The onset of the sharpest downward deflection of the intrinsic deflection was nearly synchronous with the onset of the sharp upstroke of the membrane action potential. The small initial slow component of the membrane action potential was surmised to reflect the potential change extrinsic to the cell penetrated.

\section{Acknowledgement}

The author wishes to express appreciation to Professor Susumu Hibino (The First Department of Internal Medicine, School of Medicine, Nagoya University), Professor Hideo Toyoshima and Assistant Professor Kazuo Yamada (The Research Institute of Environmental Medicine, Nagoya University) for their valuable instructions and also to Dr. A. Miyauchi and Dr. H. Horibe for their cooperations.

\section{REFERENCES}

1. Miyauchi, A.: Jap. Heart J. 3: 357, 1962.

2. Toyoshima, H., Yamada, K., Horiba, M., Miyauchi, A., Sakaida, Y., Horibe, H., Nonogawa, A., Oishi, H., Ishikawa, K., Muraki, H., and Toyama, J. : Ann. Rept. Research Inst. Environment. Med. Nagoya Univ. 11 : 39, 1963.

3. Horibe, H. : Jap. Circulat. J. 25: 6, 1961.

4. Bachmann, G.: Ann. Int. Med. 14: 1702, 1941.

5. Matsuoka, S.: Jap. Circulat. J. 21 : 303, 1957.

6. Horiba, M.: Jap. Heart J. 4 : 333, 1963.

7. Easton, D.M.: Am. J. Physiol. $197:$ 163, 1959.

8. Prinzmetal, M., Toyoshima, H., Ekmekci, A., and Nagaya, T. : Clin. Sci. 23: 489, 1962.

9. Sano, T.: Jap. Circulat. J. $20: 507,1956$.

10. Woodbury, L.A., Hecht, H.H., and Christopherson, A.R. : Am. J. Physiol. 164 : $307,1951$.

11. Toyoshima, H., Yamada, K., Itatsu, H., and Mizuno, Y.: Jap. Circulat. J. 18 : 37, 1954.

12. Paes de Carvalho, A., Mello, W.C., and Hoffman, B.F.: Am. J. Physiol. 196 : 483, 1959.

13. Glomset, D.J and Glomset, A.T.A.: Am. Heart J. $20: 389,1940$.

14. Patten, B.M.: Univ. Michigan M. Bull. 22: 1, 1956.

15. Hoffman, B.F., Paes de Carvalho, A., Mello, W.A., and Cranefield, P.F.: Circulat. Res. 7 : 11 , 1959.

16. Paes de Canvalho, A. and de Almeida, D.F.: Circulat. Res. 8 : 801, 1960. 